International Journal of Electrical and Power Engineering 5 (2): 102-107, 2011

ISSN: 1990-7958

(C) Medwell Journals, 2011

\title{
Stator Fault Detection and Diagnosis of a Induction Motor Using Neuro Fuzzy Logic
}

\author{
M. Sreedevi and P. Jeno Paul \\ Anna University of Tecnology, Tamil Nadu, India
}

\begin{abstract}
Many researches dealt with the problem of induction motors fault detection and diagnosis. The major difficulty is the lack of an accurate model that describes a fault motor. Moreover, experienced engineers are often required to interpret measurement data that are frequently inconclusive. A neuro fuzzy logic approach may help to diagnose induction motor faults. In fact, neuro fuzzy logic is reminiscent of human thinking processes and natural language enabling decisions to be made based on vague information. Therefore, this study applies fuzzy logic to induction motors fault detection and diagnosis. The motor condition is described using linguistic variables. Neuro fuzzy subsets and the corresponding membership functions describe stator current amplitudes. A knowledge base, comprising rule and data bases is built to support the fuzzy inference. The induction motor condition is diagnosed using a compositional rule of fuzzy inference using Matlab/ Simulink.
\end{abstract}

Key words: Induction motor, neuro fuzzy logic, condition monitoring, stator fault, data base, India

\section{INTRODUCTION}

One of the most widely used techniques for obtaining information on the health state of induction motors is based on the processing of stator line current. Typically in the motor fault diagnosis process, sensors are used to collect time domain current signals. The diagnostic expert then uses both time domain and frequency domain signals to study the motor condition and determines what faults are present (Siddique et al., 2005). However, experienced engineers are often required to interpret measurement data that are frequently inconclusive. A neuro fuzzy logic approach may help to diagnose induction motor faults.

In fact, fuzzy logic is reminiscent of human thinking processes and natural language enabling decisions to be made based on vague information. Neuro fuzzy logic allows items to be described as having a certain membership degree in a set. This allows a computer which is normally constrained to 1 and 0 to delve into the continuous realm. When conducting fault diagnosis, there are several situations in which an object is not obviously good or bad but may fall into some interior range 6-81. According to the fact that induction motor condition interpretation is a fuzzy concept during the past few years, researchers have proposed some fuzzy logic based diagnosis approaches (Pereira et al., 2005). A major difficulty is the lack of a well processing of fuzzy input data. On-line condition monitoring involves taking measurements on a machine while it is operating in order to detect faults with the aim of reducing both unexpected failures and maintenance costs. This study surveys, the current trends in on-line fault detection and diagnosis of induction machines and identifies future research are as using neuro fuzzy control. With the rapid development in computer hardware and software, new simulation packages which are faster and more user friendly are now available. This study discusses the use of one such product, the Simulink software of Matlab in the dynamic modeling of the induction motor.

The main advantage of Simulink over other programming software's is that instead of compilation of program code, the Simulation model is built up systematically by means of basic function blocks. Through a convenient Graphical User Interface (GUI), the function blocks can be created, linked and edited easily using menu commands, the keyboard and an appropriate pointing device (such as the mouse). A set of machine differential equations can thus be modeled by interconnection of appropriate function blocks, each of which performing a specific mathematical operation. Programming efforts are drastically reduced and the debugging of errors is easy. Since, Simulink is a model operation programmer, the simulation model can be easily developed by addition of new sub-models to cater for various control functions. As a sub-model, the induction motor could be incorporated in a complete electric motor drive system.

Corresponding Author: M. Sreedevi, Anna University of Tecnology, Tamil Nadu, India 
Classification of faults: Electrical faults such as broken rotor bars, rotor unbalances, bearing faults and stator winding faults can be observed and driven load conditions can be determined.

Bearing faults: The majority of electrical machines use ball or rolling element bearings and these are one of the most common causes of failure. These bearings consist of an inner and outer ring with a set of balls or rolling elements placed in raceways rotating inside these rings. Faults in the inner raceway, outer raceway or rolling elements will produce unique frequency components in the measured machine vibration and other sensor signals. These bearing faul frequencies are functions of the bearing geometry and the running speed. Bearing faults can also cause rotor eccentricity (Mehala and Dahiya, 2009).

Stator faults: Almost $40 \%$ of all reported induction machine failures fall into this category. The stator winding consists of coils of insulated copper wire placed in the stator slots.

Stator winding faults are often caused by insulation failure between two adjacent turns in a coil. This is called a turn-to-turn fault or shorted turn. The resultant induced currents produce extra heating and cause an imbalance in the magnetic field in the machine. If undetected, the local heating will cause further damage to the stator insulation until catastrophic failure occurs. The unbalanced magnetic field can also result in excessive vibration that can cause premature bearing failures: The stator is subjected to various stresses such as thermal, electrical, mechanical and environmental which severely affects the stator condition leading to faults (Ilonen et al., 2005). The stator defects/faults can be broadly classified into the following two categories:

- Laminations (core hot spot, core slackening), frame (vibration, circulating currents, loss of coolants, earth faults )

- Stator windings defects/faults are the most common defects/faults of stator windings related to either the end winding portion or the slot portion

- End-winding portion (local damage to insulation, fretting of insulation, contamination of insulation by moisture, oil or dirt, damage to connectors, cracking of insulation, discharge erosion of insulation, displacement of conductors, turn-to-turn faults)

- Slot portion (fretting of insulation, displacement of conductors)

\section{INDUCTION MOTOR MODELLING}

The motor is considered as a three-phase squirrel cage induction machine having three phases in the stator and $\mathrm{Nr}$ phases in the rotor where $\mathrm{Nr}$ is the number of rotor slots. The stator is viewed as a wye connection and the stator windings are sinusoidally distributed. The rotor is viewed as $\mathrm{Nr}$ identical loops. So, the model is suitable to simulate a squirrel cage induction motor as a wound rotor. In order to have a model, we assert the following assumptions (Fig. 1):

- Air-gap is uniform

- There is no space harmonic

- The magnetic material is linear (negligible saturation)

- There is no eddy current

- The magnetic circuit is symmetric

The voltage equations for a three-phase induction machine can be expressed by stator equation as:

$$
\begin{aligned}
& V_{A}=R_{A_{A}} i_{A}+\frac{d \lambda_{A}}{d t} \\
& V_{B}=R_{B} i_{B}+\frac{d \lambda_{B}}{d t} \\
& V_{C}=R_{C} i_{C}+\frac{d \lambda_{C}}{d t}
\end{aligned}
$$

Rotor equation is:

$$
\begin{aligned}
& V_{a}=R_{a} i_{a}+\frac{d \lambda_{a}}{d t} \\
& V_{b}=R_{b} i_{b}+\frac{d \lambda_{b}}{d t} \\
& V_{c}=R_{c} i_{c}+\frac{d \lambda_{c}}{d t}
\end{aligned}
$$

The flux linkages associated with the interactions between stator and rotor windings are represented by:

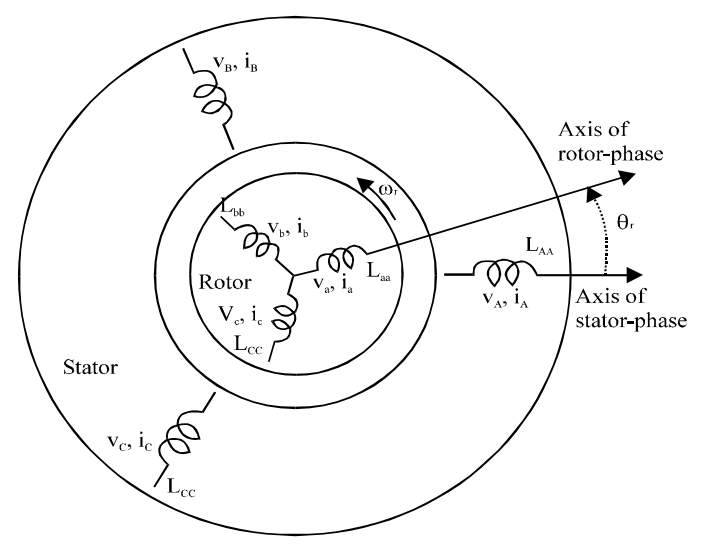

Fig. 1: Three phase induction motor 
Stator:

$$
\begin{aligned}
\lambda_{\mathrm{A}}= & \mathrm{L}_{\mathrm{AA}} \mathrm{i}_{\mathrm{A}}+\mathrm{L}_{\mathrm{AB}} \mathrm{i}_{\mathrm{B}}+\mathrm{L}_{\mathrm{AC}} \mathrm{i}_{\mathrm{C}}+\mathrm{L}_{\mathrm{Aa}} \cos \left(\theta_{\mathrm{r}}\right) \mathrm{i}_{\mathrm{a}}+ \\
& \mathrm{L}_{\mathrm{Ab}} \cos \left(\theta_{\mathrm{r}}+\frac{2 \Pi}{3}\right) \mathrm{i}_{\mathrm{b}}+\mathrm{L}_{\mathrm{AC}} \cos \left(\theta_{\mathrm{r}}-\frac{2 \Pi}{3}\right) \mathrm{i}_{\mathrm{c}} \\
\lambda_{\mathrm{B}}= & \mathrm{L}_{\mathrm{BA}} \mathrm{i}_{\mathrm{A}}+\mathrm{L}_{\mathrm{BB}} \mathrm{i}_{\mathrm{B}}+\mathrm{L}_{\mathrm{BC}} \mathrm{i}_{\mathrm{C}}+\mathrm{L}_{\mathrm{Ba}} \cos \left(\theta_{\mathrm{r}}-\frac{2 \Pi}{3}\right) \mathrm{i}_{\mathrm{a}}+ \\
& \mathrm{L}_{\mathrm{Bb}} \cos \left(\theta_{\mathrm{r}}\right) \mathrm{i}_{\mathrm{b}}+\mathrm{L}_{\mathrm{Bc}} \cos \left(\theta_{\mathrm{r}}+\frac{2 \Pi}{3}\right) \mathrm{i}_{\mathrm{c}} \\
\lambda_{\mathrm{C}}= & \mathrm{L}_{\mathrm{CA}} \mathrm{i}_{\mathrm{A}}+\mathrm{L}_{\mathrm{CB}} \mathrm{i}_{\mathrm{B}}+\mathrm{L}_{\mathrm{CC}} \mathrm{i}_{\mathrm{C}}+\mathrm{L}_{\mathrm{Ca}} \cos \left(\theta_{\mathrm{r}}+\frac{2 \Pi}{3}\right) \mathrm{i}_{\mathrm{a}}+ \\
& \mathrm{L}_{\mathrm{Cb}} \cos \left(\theta_{\mathrm{r}}-\frac{2 \Pi}{3}\right) \mathrm{i}_{\mathrm{b}}+\mathrm{L}_{\mathrm{Cc}} \cos \left(\theta_{\mathrm{r}}\right) \mathrm{i}_{\mathrm{c}}
\end{aligned}
$$

Rotor:

$$
\begin{aligned}
& \lambda_{\mathrm{a}}= \mathrm{L}_{\mathrm{aA}} \cos \left(\theta_{\mathrm{r}}\right) \mathrm{i}_{\mathrm{A}}+\mathrm{L}_{\mathrm{aB}} \cos \left(\theta_{\mathrm{r}}+\frac{2 \Pi}{3}\right) \mathrm{i}_{\mathrm{B}}+ \\
& \mathrm{L}_{\mathrm{aC}} \cos \left(\theta_{\mathrm{r}}-\frac{2 \Pi}{3}\right) \mathrm{i}_{\mathrm{C}}+\mathrm{L}_{\mathrm{Aa}} \mathrm{i}_{\mathrm{a}}+\mathrm{L}_{\mathrm{Ab}} \mathrm{i}_{\mathrm{b}}+\mathrm{L}_{\mathrm{Ac}} \mathrm{i}_{\mathrm{c}} \\
& \lambda_{\mathrm{b}}=\mathrm{L}_{\mathrm{bA}} \cos \left(\theta_{\mathrm{r}}+\frac{2 \Pi}{3}\right) \mathrm{i}_{\mathrm{A}}+\mathrm{L}_{\mathrm{aB}} \cos \left(\theta_{\mathrm{r}}\right) \mathrm{i}_{\mathrm{B}}+ \\
& \mathrm{L}_{\mathrm{aC}} \cos \left(\theta_{\mathrm{r}}-\frac{2 \Pi}{3}\right) \mathrm{i}_{\mathrm{C}}+\mathrm{L}_{\mathrm{ba}} \mathrm{i}_{\mathrm{a}}+\mathrm{L}_{\mathrm{bb}} \mathrm{i}_{\mathrm{b}}+\mathrm{L}_{\mathrm{bc}} \mathrm{i}_{\mathrm{c}} \\
& \lambda_{\mathrm{c}}=\mathrm{L}_{\mathrm{bA}} \cos \left(\theta_{\mathrm{r}}-\frac{2 \Pi}{3}\right) \mathrm{i}_{\mathrm{A}}+\mathrm{L}_{\mathrm{cB}} \cos \left(\theta_{\mathrm{r}}+\frac{2 \Pi}{3}\right) \mathrm{i}_{\mathrm{B}}+ \\
& \mathrm{L}_{\mathrm{cC}} \cos \left(\theta_{\mathrm{r}}\right) \mathrm{i}_{\mathrm{C}}+\mathrm{L}_{\mathrm{ca}} \mathrm{i}_{\mathrm{a}}+\mathrm{L}_{\mathrm{cb}} \mathrm{i}_{\mathrm{b}}+\mathrm{L}_{\mathrm{cc}} \mathrm{i}_{\mathrm{c}}
\end{aligned}
$$

The electromechanical torque equation is:

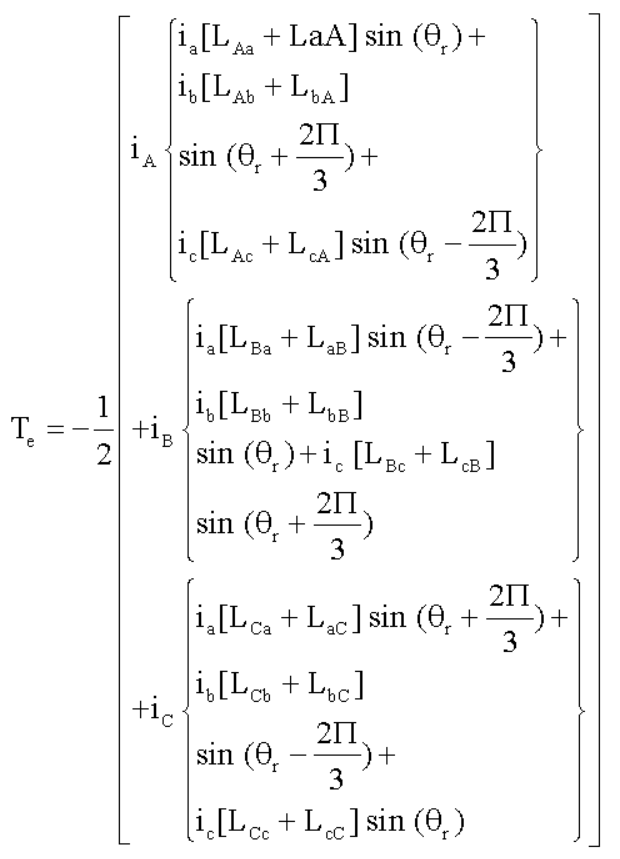

The dynamic load equation is:

$$
\begin{aligned}
& \mathrm{T}_{\mathrm{e}}-\mathrm{T}_{\mathrm{L}}=\mathrm{J} \frac{\mathrm{d} \omega_{\mathrm{r}}}{\mathrm{dt}}+\mathrm{D} \omega_{\mathrm{r}} ; \frac{\mathrm{d} \omega_{\mathrm{r}}}{\mathrm{dt}}=\frac{\mathrm{T}_{\mathrm{e}}-\mathrm{T}_{\mathrm{L}}}{\mathrm{J}} ; \\
& \omega_{\mathrm{r}}=\frac{1}{\mathrm{~J}} \int\left(\mathrm{T}_{\mathrm{e}}-\mathrm{T}_{\mathrm{L}}\right) \mathrm{dt}
\end{aligned}
$$

\section{INDUCTION MACHINE MODEL IN A THREE-PHASE REFERENCE FRAME}

When induction machines are expressed in three-phase axes, many of the inductances are function of the rotor displacement and therefore, functions of rotor speed and time as shown in the following.

Stator inductances: It is assumed that the air gap of the induction machine is uniform and the stator and rotor windings are sinusoidally distributed, all the stator self-inductances are identical.

$$
\mathrm{L}_{\mathrm{AA}}=\mathrm{L}_{\mathrm{BB}}=\mathrm{L}_{\mathrm{CC}}=\mathrm{L}_{1 \mathrm{~s}}+\mathrm{L}_{\mathrm{ms}}
$$

The mutual inductance between any two stator windings is the same due to symmetry:

$$
\begin{aligned}
& \mathrm{L}_{\mathrm{AB}}=\mathrm{L}_{\mathrm{BA}}=-0.5 \mathrm{~L}_{\mathrm{ms}} \\
& \mathrm{L}_{\mathrm{BC}}=\mathrm{L}_{\mathrm{CB}}=-0.5 \mathrm{~L}_{\mathrm{ms}} \\
& \mathrm{L}_{\mathrm{CA}}=\mathrm{L}_{\mathrm{AC}}=-0.5 \mathrm{~L}_{\mathrm{ms}}
\end{aligned}
$$

Rotor inductances: In the same manner to that given for the stator, the rotor self-inductances and mutual inductances are:

$$
\begin{gathered}
\mathrm{L}_{\mathrm{aa}}=\mathrm{L}_{\mathrm{bb}}=\mathrm{L}_{\mathrm{cc}}=\mathrm{L}_{\mathrm{lr}}+\mathrm{L}_{\mathrm{mr}} \\
\mathrm{L}_{\mathrm{ab}}=\mathrm{L}_{\mathrm{ba}}=-0.5 \mathrm{~L}_{\mathrm{mr}} \\
\mathrm{L}_{\mathrm{bc}}=\mathrm{L}_{\mathrm{cb}}=-0.5 \mathrm{~L}_{\mathrm{mr}} \\
\mathrm{L}_{\mathrm{ca}}=\mathrm{L}_{\mathrm{ac}}=-0.5 \mathrm{~L}_{\mathrm{mr}} \\
\mathrm{L}_{\mathrm{Aa}}=\mathrm{L}_{\mathrm{Bb}}=\mathrm{L}_{\mathrm{Cc}}=\mathrm{L}_{\mathrm{msr}} \cos \theta_{\mathrm{r}} \\
\mathrm{L}_{\mathrm{Ac}}=\mathrm{L}_{\mathrm{Ba}}=\mathrm{L}_{\mathrm{Cb}}=\mathrm{L}_{\mathrm{msr}} \cos \left(\theta_{\mathrm{r}}-120^{\circ}\right) \\
\mathrm{L}_{\mathrm{A} b}=\mathrm{L}_{\mathrm{Bc}}=\mathrm{L}_{\mathrm{Ca}}=\mathrm{L}_{\mathrm{msr}} \cos \left(\theta_{\mathrm{r}}+120^{\circ}\right)
\end{gathered}
$$

The mutual inductance between a stator winding and any rotor winding varies sinusoidally with rotor position.

\section{IMPLEMENTATIONOFCONDITIONMONITORING ON INDUCTION MOTOR}

Induction motors are a critical component of many industrial processes and are frequently integrated in commercially available equipment and industrial 


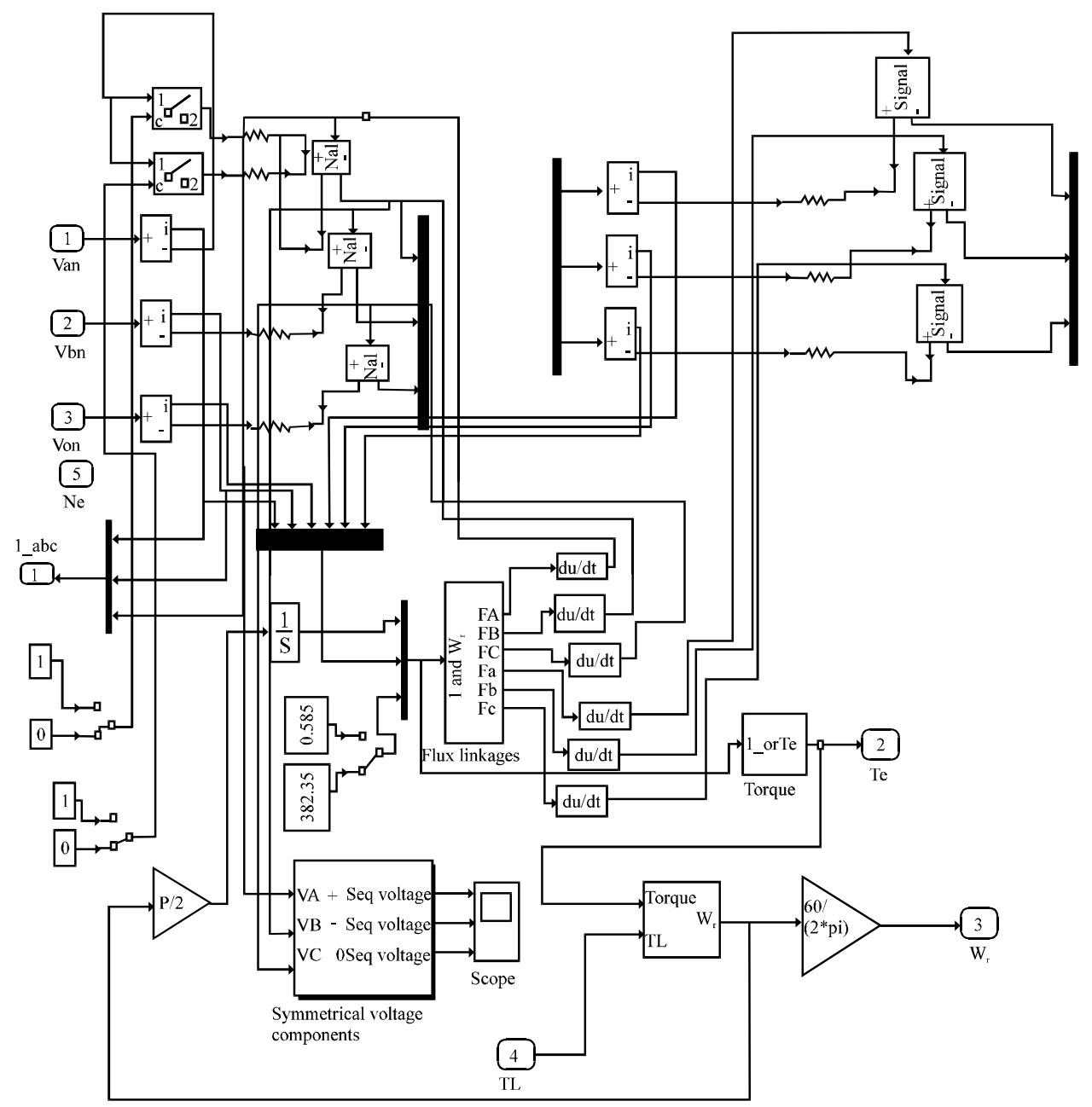

Fig. 2: Simulink model of induction motor subsystems

processes. The studies of induction motor behavior during abnormal conditions and the possibility to diagnose different types of faults have been a challenging topic for many electrical machine researchers. The Motor Current Signature Analysis (MCSA) is considered the most popular Fault detection method now a day because it can easily detect the common machine fault such as turn to turn short circuit, cracked broken rotor bars, bearing deterioration, etc. This study presents theory and some experimental results of motor current signature analysis. The MCSA uses the current spectrum of the machine for locating characteristic fault frequencies. The spectrum is obtained using a Fast Fourier Transformation (FFT) that is performed on the signal under analysis. The fault frequencies that occur in the motor current spectra are unique for different motor faults (Fig. 2).

Neuro fuzzy logic approach: In recent years, ANN's have generated considerable interest in the field of engineering

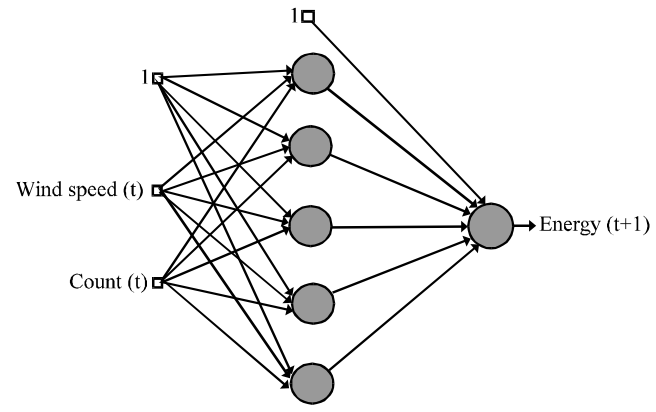

Fig. 3: The developed network architecture

as problem-solving tools. The fundamental element is a neuron which has multiple inputs and a single output. Each input is multiplied by a weight, the inputs are summed and this quantity is operated on by the transfer function of the neuron to generate the output. The output is sometimes referred to as an activity level. In this study, the multilayer feed forward NN(FFNN) is shown in Fig. 3. 
The develped network architecure that has one hidden layer is used. The bias unit, whose activity level is fixed at one is connected to all neurons in the hidden and output layer to adjust the weighted sum input of each neuron. The number of neurons in the input and the output layer is determined by each application and the number of neurons in the hidden layer must be adjusted during the learning phase so that the network can be trained efficiently. The activity level of the jth neuron is obtained as:

$$
v_{j}=f_{j}\left(\text { net }_{j}\right)=f_{i}\left[\sum_{i}\left(\omega_{j i} x_{i}\right)+b_{j}\right]
$$

Where:

$\mathrm{v}_{\mathrm{j}} \quad=$ Activity level (output) of the jth neuron

$\left(\right.$ net $\left._{j}\right)=$ Input of the $\mathrm{jth}$ neuron

$\mathrm{f}_{\mathrm{i}}=$ Transfer function of the $j$ th neuron

$\omega_{\mathrm{ji}}=$ Connection weight from the ith neuron to the jth neuron

$\mathrm{x}_{\mathrm{i}}=$ Activity level of the ith neuron in the prior layer

$b_{j}=$ connection weight from the bias unit to the jth neuron

The sigmoid function is used as the transfer function in this study. The back propagation algorithm is used to train the network (Gill et al., 2010). The connection weights such as $\omega_{\mathrm{ji}}$ and $\mathrm{bj}$ are adjusted so that the average squared error between the network output and the desired output (target) for a given reference input is minimized. Learning continues iteratively until the sum of the squared error is below a certain goal. The incremental change of weight from the ith neuron to the $\mathrm{jth}$ is computed by:

$$
\Delta \omega_{i j}(t+1)=\eta \delta_{j} o_{i}+\alpha \Delta \omega_{i j}(t)
$$

Where:

$\Delta \omega_{\mathrm{ij}}(\mathrm{t}+1)=$ Incremental change in the weight $\omega_{\mathrm{ij}}$ at time $\mathrm{t}$

$\eta \quad=$ Learning rate (usually a constant)

$\alpha \quad=$ Momentum (usually a constant)

Fuzzy logic is function to the diagnosis of induction motor stator and phase conditions, based on the amplitude features of stator currents. This method has been chosen because fuzzy logic has proven ability in mimicking human decisions and the stator voltage and phase condition monitoring problem has typically been solved.

Fuzzy and membership functions construction: Fuzzy rules and membership functions are constructed by observing the data set. For the measurements related to the stator currents, more insight into the data is needed, so, membership functions will be generated for zero, small, medium and big. For the measurement related to the stator condition, it is only necessary to know if the stator condition is good, damaged or seriously damaged. The optimized membership functions for this problem are shown. Once the form of the initial membership functions has been determined, the fuzzy if then rules can be derived. In this study, two faults have been investigated; stator voltage unbalance and open phase. These rules have been optimized so as to cover all the healthy and the faulty cases. For the study, we have obtained the following 14 if-then rules:

Rule (1): If $I_{a}$ is $Z$ then CM is $S D$

Rule (2): If $I_{b}$ is $Z$ then CM is SD

Rule (3): If $I_{c}$ is $Z$ then CM is $S D$

Rule (4): If $I_{a}$ is $B$ then CM is SD

Rule (5): If $I_{b}$ is $B$ then CM is SD

Rule (6): If $I_{c}$ is B then CM is SD

Rule (7): If $I_{a}$ is $S$ and Ib is $S$ and Ic is $M$ then CM is D

Rule (8): If $I_{a}$ is $S$ and Ib is $M$ and Ic is $M$ then CM is D

Rule (9): If $I_{a}$ is $M$ and Ib is $S$ and Ic is $M$ then CM is D

Rule (10): If $I_{a}$ is $M$ and Ib is M and Ic is M then CM is G Rule (11): If $I_{a}$ is $S$ and $I b$ is $S$ and Ic is $S$ then $C M$ is $G$ Rule (12): If $\mathrm{I}_{\mathrm{a}}$ is $\mathrm{S}$ and $\mathrm{Ib}$ is $\mathrm{M}$ and Ic is $\mathrm{S}$ then $\mathrm{CM}$ is $\mathrm{D}$ Rule (13): If $I_{a}$ is $M$ and Ib is $S$ and Ic is $S$ then CM is D Rule (14): If $I_{a}$ is $M$ and Ib is $M$ and Ic is $S$ then CM is D

\section{SIMULATION RESULTS}

Figure 4 shows the current flow thorough the three phase induction motor with out and fault. The total simulation time is $1 \mathrm{sec}$. During the motor starting I (abc) takes large current $(10 \mathrm{~A})$ as shown in Fig. 4. When the single line fault accrue the stator the current goes to low as shown in Fig. 5. Figure 6 shows the single line fault accured in the stator winding the neuro fuzzy based controller extract the fault current as shown in blue color.

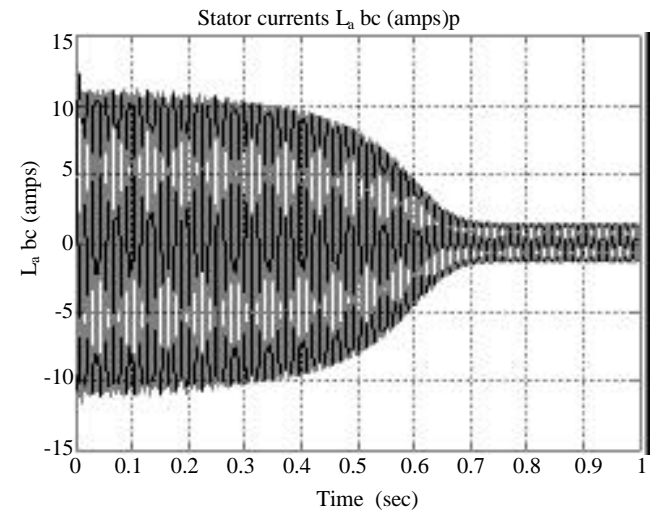

Fig. 4: Three phase current for a healthy motor 


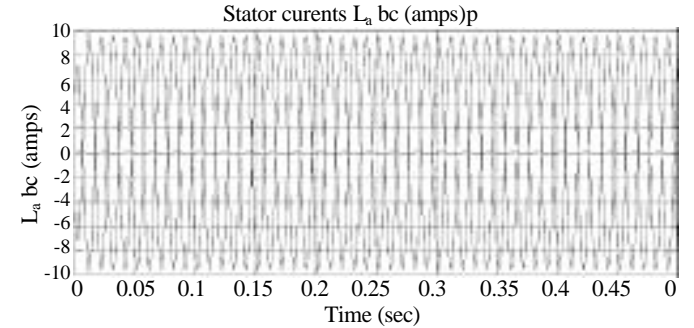

Fig. 5: Three phase current for a single-phase fault

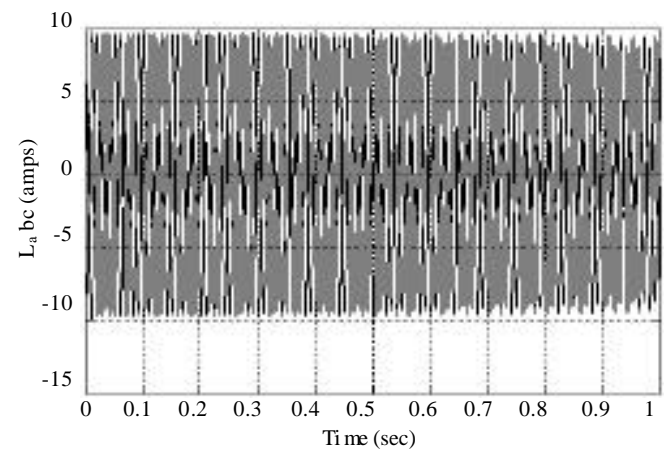

Fig. 6: Three phase current for a single line fault

\section{CONCLUSION}

A method of using neuro fuzzy logic to interpret current sensors signal of induction motor for its stator condition monitoring was presented. Correctly processing theses current signals and inputting them to a fuzzy decision system achieved high diagnosis accuracy. There is most likely still room for improvement by using an intelligent means of optimization.

\section{REFERENCES}

Gill, J., B. Singh and S. Singh, 2010. Training back propagation neural networks with genetic algorithm for weather forecasting. Proceedings of the 8th International Symposium on Intelligent Systems and Informatics, Sept. 10-11, Subotica, pp: 465-469.

Ilonen, J., J.K. Kamarainen, T. Lindh, J. Ahola, H. Kalviainen and J. Partanen, 2005. Diagnosis tool for motor condition monitoring. IEEE Trans. Ind. Appl., 41: 963-971.

Mehala, N. and R. Dahiya, 2009. Condition monitoring methods, failure identification and analysis for Induction machines. Int. J. Circuits Syst. Signal Process, 3: 10-17.

Pereira, L.A., D.D.S. Gazzana and L.F.A. Pereira, 2005. Motor current signature analysis and fuzzy logic applied to the diagnosis of short-circuit faults in induction motors. Proceedings of the 31st Annual IEEE Industrial Electronics Society Conference, Nov. 6-10, USA., pp: 6-6.

Siddique, A., G.S. Yadava and B. Singh, 2005. A review of stator fault monitoring techniques of induction motors. IEEE Trans. Energy Convers., 20: 106-114. 